\title{
The global prevalence of intimate partner homicide: a systematic review
}

\author{
Heidi Stöckl, Karen Devries, Alexandra Rotstein, Naeemah Abrahams, Jacquelyn Campbell, Charlotte Watts, Claudia Garcia Moreno
}

\begin{abstract}
Summary
Background Homicide is an important cause of premature mortality globally, but evidence for the magnitude of homicides by intimate partners is scarce and hampered by the large amount of missing information about the victim-offender relationship. The objective of the study was to estimate global and regional prevalence of intimate partner homicide.
\end{abstract}

Methods A systematic search of five databases (Medline, Global Health, Embase, Social Policy, and Web of Science) yielded 2167 abstracts, and resulted in the inclusion of 118 full-text articles with 1122 estimates of the prevalence of intimate partner homicide after double-blind screening. All studies were included that reported the number or proportion of women or men who were murdered by an intimate partner in a country, province, or town, using an inclusive definition of an intimate partner. Additionally, a survey of official sources of 169 countries provided a further 53 estimates. We selected one estimate per country-year using a quality assessment decision algorithm. The median prevalence of intimate partner homicide was calculated by country and region overall, and for women and men separately.

Findings Data were obtained for 66 countries. Overall 13.5\% (IQR 9.2-18.2) of homicides were committed by an intimate partner, and this proportion was six times higher for female homicides than for male homicides $(38.6 \%$, $30 \cdot 8-45 \cdot 3$, vs $6 \cdot 3 \%, 3 \cdot 1-6 \cdot 3$ ). Median percentages for all (male and female) and female intimate partner homicide were highest in high-income countries (all, 14.9\%, 9.2-18.2; female homicide, $41 \cdot 2 \%, 30 \cdot 8-44 \cdot 5$ ) and in southeast Asia $(18 \cdot 8 \%, 11 \cdot 3-18 \cdot 8 ; 58 \cdot 8 \%, 58 \cdot 8-58 \cdot 8)$. Adjustments to account for unknown victim-offender relationships generally increased the prevalence, suggesting that results presented are conservative.

Interpretation At least one in seven homicides globally and more than a third of female homicides are perpetrated by an intimate partner. Such violence commonly represents the culmination of a long history of abuse. Strategies to reduce homicide risk include increased investment in intimate partner violence prevention, risk assessments at different points of care, support for women experiencing intimate partner violence, and control of gun ownership for people with a history of violence. Improvements in country-level data collection and monitoring systems are also essential, because data availability and quality varied strongly across regions.

Funding WHO, Sigrid Rausing Trust, and the UK Economic and Social Research Council.

\section{Introduction}

In 2010, nearly half a million people are estimated to have been murdered worldwide, and $80 \%$ of homicide victims were male. ${ }^{1}$ Strategies to prevent homicide therefore commonly focus on male victims and gang and male-on-male street violence. ${ }^{2,3}$ However, women and men are also at risk of being murdered by their intimate partners. For women, in particular, research suggests that their greatest risk of homicide is from a current or former intimate partner. ${ }^{4,5}$ For example, in the USA, a country with high national homicide rates, in 2008, around $45 \%$ of female and $5 \%$ of male homicides were committed by an intimate partner. ${ }^{6}$ Similarly, in the UK in $2009,54 \%$ of female and $5 \%$ of male homicides were perpetrated by an intimate partner. ${ }^{7}$ However, evidence from outside North America is scarce; one exception is a national mortuary study of female homicides in South Africa, which found that, in 1999 and 2009, around 50\% of murdered women were killed by an intimate partner. ${ }^{8}$

Establishing of the prevalence of intimate partner homicide is hampered by many factors, including data availability and quality. In many countries, particularly low-income and middle-income settings, national data for homicides are incomplete. Homicide statistics are mainly collected by the police or through mortuaries, and information about the relationship between the victim and offender is not commonly recorded, despite its importance for prevention strategies..$^{9,10}$

Previous efforts to provide an overview of the magnitude of intimate partner homicide worldwide ${ }^{1,11-14}$ have been limited, because they have focused exclusively on female intimate partner homicides and solely used reported data from national statistical offices, without considering the potential implications of missing reported data. Evidence from the published literature also has not been incorporated into these estimates. As part of a larger assessment of the global health burden of exposure to intimate partner violence for the Global Burden of Diseases, Injuries, and Risk Factor 2010 study, ${ }^{15}$ in this Article we present the findings from a systematic review of published evidence and a survey of 169 national statistical offices, summarising global and regional estimates of the

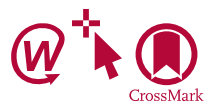

Published Online June 20, 2013 http://dx.doi.org/10.1016/ S0140-6736(13)61030-2 See Online/Comment http://dx.doi.org/10.1016/ S0140-6736(13)61255-6

Social and Mathematical Epidemiology Group, Department of Global Health and Development, London School of Hygiene and Tropica Medicine, London, UK (H Stöckl PhD, K Devries PhD Prof (Watts PhD); Michael G DeGroote School of Medicine, McMaster University, Hamilton, ON, Canada (A Rotstein MSc); Gender and Health Research Unit, South African Medical Research Council, Cape Town, South Africa (Prof N Abrahams PhD); Johns Hopkins University School of Nursing, Baltimore, MD, USA (Prof) Campbell PhD) and Sexual Health, Gender, Reproductive Rights and Adolescence, Department of Reproductive Health and Research, WHO, Geneva, Switzerland (C Garcia Moreno MD)

Correspondence to: Dr Heidi Stöckl, Social and Mathematical Epidemiology Group, Department of Global Health and Development, London School of Hygiene and Tropical Medicine, London WC1H 9SH, UK heidi.stoeckl@Ishtm.ac.uk 
For WHO mortality statistics see http://appswhoint/ healthinfo/statistics/mortality/ prevalence of intimate partner homicide by sex and overall. Because of the methodological challenges of obtaining these estimates, we also explore how the estimates might vary, dependent on how missing information on the victim-offender relationship is accounted for.

\section{Methods \\ Study design}

Data for the prevalence of intimate partner homicide were compiled with two methods. Firstly, a systematic review following the PRISMA guidelines ${ }^{16}$ of the databases Medline, Global Health, Embase, Social Policy, and Web of Science was used to identify all published studies between Jan 1, 1990, and Dec 31, 2011. The search included the terms: "partner" or "partners" or "expartners" or "ex-partner" or "husband" or "husbands" or "wife" or "wives" or "co-habiting" or "common-law" or "married" or "marital" or "marriage" or "divorce" or "divorced" or "couple" or "couples" or "boyfriend*" or "girlfriend $*$ " or "spouse" or "spouses" or "lover" or

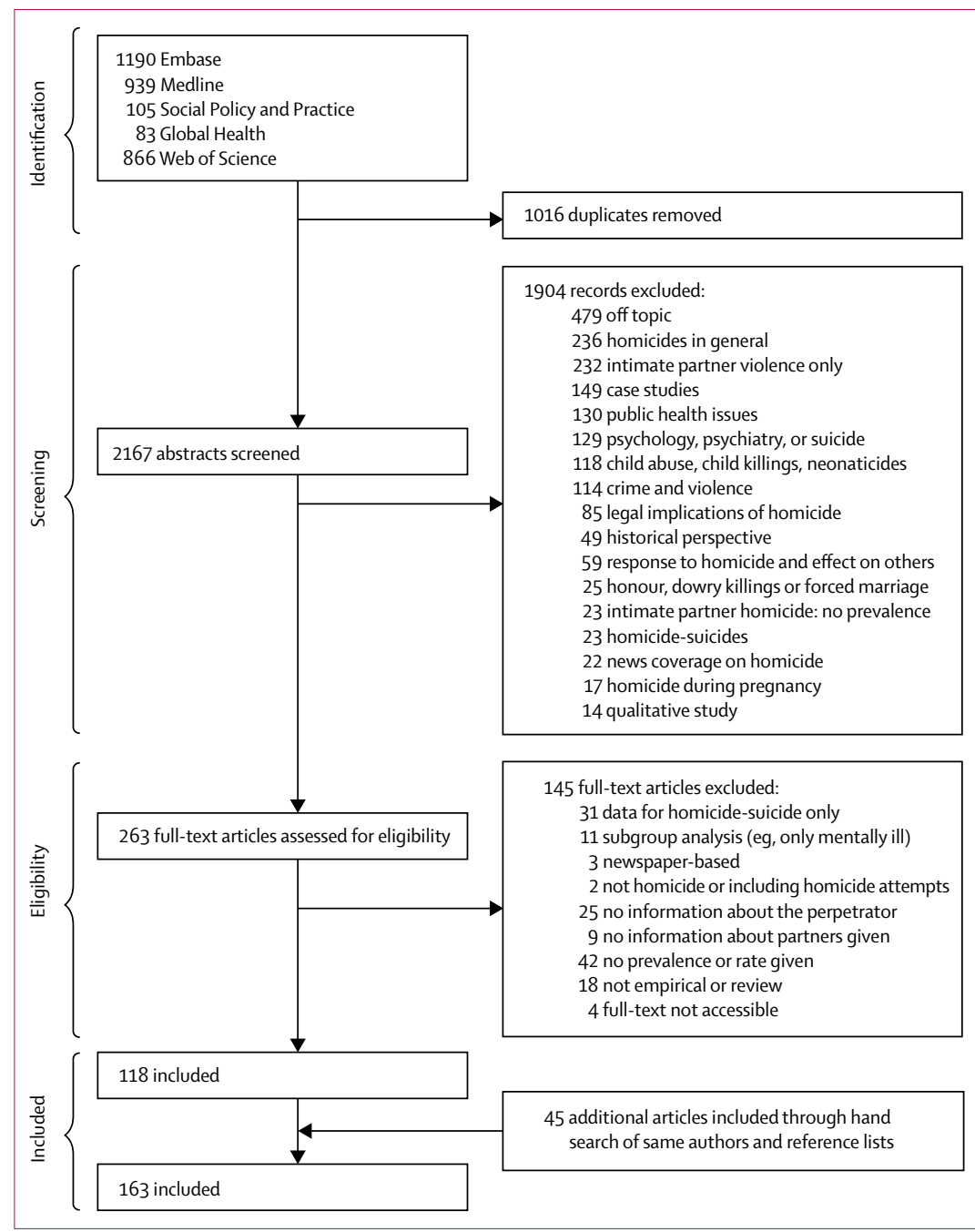

Figure 1: Systematic review "spousal" or "partner violence" or "marriage" combined with the terms "homicide" or "murder*" or "killings" or "killing" or "genocide*" or "deaths wrongful" or "wrongful deaths" or "death wrongful" or "homicide*" or "wrongful death" or "femicide" or "uxoricide" or "spouse homicide". The citations of included articles were also searched.

Studies were included if they stated a number or proportion of women or men who were murdered by an intimate partner in a country, province, or town based on either national databases, national representative studies, or studies based on samples from police, courts, mortuaries, or prisons. An inclusive definition of intimate partner was used, including former and same-sex partners, although same-sex partners were only included in a handful of studies of industrialised countries. We excluded studies that only reported data collected from newspaper reports; those that did not differentiate between attempted and completed homicides; and those that did not explicitly identify intimate partners as perpetrators. Figure 1 provides details of the inclusion and exclusion criteria and the numbers of papers reviewed.

Two authors (HS and AR) screened the 2167 abstracts and the resulting 263 full texts independently and resolved any disagreements by discussion. 118 studies were finally included. HS extracted the data after the first ten studies were extracted with agreement by both HS and AR to ensure consistency. Data extraction was double-checked for studies included in the final analysis.

In addition to the systematic review, we reviewed the 169 WHO-listed countries with relevant homepages to further identify country-level data for intimate partner homicide. For this process we surveyed country statistics offices, ministries of justice, home offices, or police headquarters via email if relevant information could not be found on homepages. We downloaded 32 reports with relevant data for different years from 13 country webpages and received responses from 75 countries, resulting in usable data from 11 countries. Additionally, we made contact with experts specialising in intimate partner homicide, and extracted data from four non peer-reviewed review studies.,11,13,147 For each country and study, information about the total number of all homicides and homicides by intimate partners for men and for women and the total number of homicides with missing data for the victim-perpetrator relationship by sex was extracted. For studies $(n=35)$ in which only intimate partner homicide but not overall homicide numbers for men and women were provided, we used official country statistics $(n=20)$ or WHO mortality statistics $(n=15)$ to obtain the missing data.

\section{Analysis}

The analysis consisted of three main steps: (1) selection of one estimate per country-year; (2) calculation of prevalence of homicide by intimate partners among all homicides, and for women and men separately; and (3) exploration of the effect of missing data. 
When countries had more than one estimate available for a particular year, to avoid double-counting and to ensure that we were using estimates from the best quality studies, we developed a quality assessment decision algorithm to identify which estimate to include in the final analysis according to the following hierarchical order: (1) we chose estimates based on national representative data over provincial estimates, and provincial estimates were preferred to studies based on individual cities or mortuaries; (2) we chose estimates from data with more complete information about overall intimate partner homicides or those with data stratified by sex over those from data in which sex or overall intimate homicide numbers were missing; (3) we chose estimates that reported on all age groups and those that used inclusive definitions of homicide and intimate relationships over data that only considered narrow age ranges or specific types of homicides or intimate relationships; and (4) we preferred estimates from official country statistics that covered more years to data presented in peer-reviewed studies reporting on fewer years, which were again preferred over review reports.

About half the studies did not provide data for single years, but reported a single combined prevalence for up to 10 years, with six starting from 1989 onwards. To allow comparisons across studies and to even out fluctuations in homicide numbers over the years within a country, we used all data available since 1989 to estimate an average percentage of all homicides, with the exception of Denmark and Fiji for which combined data were only available from before 1989 .

We obtained conservative estimates of the percentage of intimate partner homicide by dividing the number of homicides for which the perpetrator had been identified as being an intimate partner by the total number of homicides. This prevalence was calculated overall, and for female and male homicides separately. This method gives a conservative estimate of rates of intimate partner homicide, because it assumes that all homicides for which the victim-offender relationship is not known were not perpetrated by an intimate partner.

If we did not have data for the proportion and distribution of homicides with missing victim-offender information, we extrapolated the data using the following hierarchical approach: (1) we inferred it from another year in the same country; (2) we derived it from other studies of the same country that had this information; and (3) we used the proportion and distribution of all other countries in the region. For countries in the western Pacific and the eastern Mediterranean region, information about the distribution of missing data from the geographically closest southeast Asia region was used.

Taking this missing information into account, we also calculated a high-level estimate and a mid-level estimate of the prevalence of intimate partner homicide. For the high-level estimate we followed the example of Riedel and colleagues ${ }^{18}$ and deducted all homicide cases with missing information about the victim-offender relationship from the total number of homicides-ie, the estimate was based on a subset of all homicides for which perpetrators were identified. This approach could potentially lead to overestimation of the proportion of intimate partner homicide cases if one assumes that intimate partner homicide cases are solved more easily and so are more likely to be reported than stranger homicides. For the mid-level estimate, we added the cases with missing information to the cases with complete data using the same distribution as for the intimate partner homicides among known cases. This approach, which has been suggested by Paulozzi and colleagues, ${ }^{19}$ assumes that the victim-offender relationship is equally missing for partner and nonpartner homicides.

We calculated regional estimates by grouping countries as per the six WHO regions and a seventh region made of the high-income countries from all regions, and then dividing the total number of intimate partner homicides by the total number of homicides in the same countries in that region.

Data were analysed with Stata version 12. Maps were constructed with ARCGIS version 10. Traditional meta-analysis techniques could not be used because nearly all the studies were representative of the whole population and not restricted to population samples. Because the percentages were skewed, we report the median percentage with IQR.

\section{Role of the funding source}

The funders of the study had no role in study design, data collection, data analysis and interpretation, or writing of the report. The corresponding author had full access to all the data in the study. HS, CW, and CGM had final responsibility for the decision to submit for publication.

\section{Results}

227 studies and databases with 1122 estimates on the prevalence of intimate partner homicide across 66 countries were included. 198 estimates were used in the analysis after choosing one estimate per country-year (appendix). Most of the 66 countries with available data for overall intimate partner homicide were from high-income countries. Few data were available for the eastern Mediterranean region, whereas the Americas had many countries contributing data for female but not for male intimate homicide (table). Most data for intimate partner homicide outside high-income countries came from provinces, cities, or individual mortuaries. Overall, we compiled data for 492340 homicides. These data confirm the established pattern that men are more likely to be murdered than are women; ${ }^{1}$ the total number of male homicides was consistently higher than female homicides. However, the pattern is different when looking at intimate partner homicide. 
Across all countries where data were compiled, we found that $13 \cdot 5 \%$ (IQR 9.2-18.2) of all homicides were committed by an intimate partner. $38 \cdot 6 \%$ (IQR 30 $\cdot 8-45 \cdot 3$ ) of female homicides were perpetrated by an intimate partner. For male homicides the proportion was much lower $(6 \cdot 3 \%, 3 \cdot 1-6 \cdot 3$; figure 2$)$. The total number of intimate partner homicides was almost always higher among women than men. Panama and Brazil were the only exceptions, where the figures were nearly equal.

The total number of homicides reported and the prevalence of intimate partner homicide across regions and by sex is shown in the table. The median percentage of intimate partner homicides among murdered women was highest in southeast Asia $(58 \cdot 8 \%, 58 \cdot 8-58 \cdot 8)$, highincome countries $(41 \cdot 2 \%, 30 \cdot 8-44 \cdot 5)$, the Americas (40.5\%, 7.5-54.8), and Africa $(40 \cdot 1 \%, 38 \cdot 6-41 \cdot 7)$. Prevalence was lower in the western Pacific region (19.1\%, 19.1-21.3), the low-income and middle-income European region $(20 \cdot 0 \%, 1 \cdot 82-37 \cdot 8)$, and the eastern Mediterranean region $(14 \cdot 4 \%, 5 \cdot 3-23 \cdot 6)$.
Among homicides with male victims, the overall median percentage of intimate partner homicide was highest in high-income countries $(6 \cdot 3 \%, 3 \cdot 1-6 \cdot 3)$, the African region $(4 \cdot 1 \%, 1 \cdot 6-6 \cdot 4)$, and the low-income and middle-income European region $(3 \cdot 6 \%, 3 \cdot 2-4 \cdot 0)$. In all other regions the median percentages were less than $2 \%$. Further details of the distribution by country and data sources are shown in the appendix.

The combined median prevalence of intimate partner homicide (men and women) was highest in high-income countries $(14.9 \%, 9 \cdot 2-18 \cdot 2)$ and southeast Asia $(18 \cdot 8 \%$, 11.3-18.8). In the low-income and middle-income European region the median percentage of intimate partner homicide was $11 \cdot 0 \%(9 \cdot 7-12 \cdot 3)$, in the Africa region $7 \cdot 3 \%(5 \cdot 6-18 \cdot 3)$, and in the western Pacific region $4 \cdot 8 \%(4 \cdot 8-9 \cdot 8)$. The lowest prevalence of male intimate partner homicide was in the Americas (0.7\%, 0 -6-9.7).

Overall $20 \cdot 5 \%$ of all homicides reported did not have information about the victim-offender relationship (21.5\% of male and $19 \cdot 8 \%$ of female homicides). If this

\begin{tabular}{|c|c|c|c|c|}
\hline & $\begin{array}{l}\text { Total homicides } \\
\text { of included } \\
\text { studies }\end{array}$ & $\begin{array}{l}\text { Conservative estimates } \\
\text { (missing cases are regarded } \\
\text { as non-partner homicides) }\end{array}$ & $\begin{array}{l}\text { Mid-level estimate (missing } \\
\text { cases are distributed as } \\
\text { known cases) }\end{array}$ & $\begin{array}{l}\text { High-level estimate } \\
\text { (analysis is restricted to } \\
\text { known cases) }\end{array}$ \\
\hline \multicolumn{5}{|c|}{ Prevalence of intimate partner homicides among male and female homicides } \\
\hline Worldwide $(\mathrm{n}=32)$ & 492340 & $13 \cdot 54 \%(9 \cdot 24-18 \cdot 23)$ & $14 \cdot 05 \%(12 \cdot 97-20 \cdot 43)$ & $16 \cdot 18 \%(14 \cdot 07-20 \cdot 73)$ \\
\hline High-income countries $(n=18)^{*}$ & 476537 & $14 \cdot 92 \%(9 \cdot 24-18 \cdot 23)$ & $18 \cdot 38 \%(12 \cdot 97-20 \cdot 43)$ & $19 \cdot 42 \%(15 \cdot 48-20 \cdot 73)$ \\
\hline Africa $(n=4)$ & 4861 & $7 \cdot 31 \%(5 \cdot 65-18 \cdot 31)$ & $11 \cdot 32 \%(8 \cdot 61-18 \cdot 58)$ & $16 \cdot 18 \%(12 \cdot 62-18 \cdot 57)$ \\
\hline Americas $(n=3)$ & 5112 & $0.72 \%(0.64-9.65)$ & $1 \cdot 33 \%(0 \cdot 85-16 \cdot 49)$ & $4 \cdot 68 \%(0 \cdot 96-33 \cdot 06)$ \\
\hline Eastern Mediterranean $(\mathrm{n}=0)$ & .. & .. & .. & .. \\
\hline Low-income and middle-income Europe $(n=2)$ & 419 & $10 \cdot 98 \%(9 \cdot 68-12 \cdot 28)$ & $11 \cdot 16 \%(9 \cdot 83-12 \cdot 48)$ & $11 \cdot 16 \%(9 \cdot 84-12 \cdot 48)$ \\
\hline Southeast Asia $(n=2)$ & 601 & $18 \cdot 75 \%(11 \cdot 26-18 \cdot 75)$ & $22 \cdot 04 \%(13 \cdot 14-22 \cdot 04)$ & $22 \cdot 74 \%(13 \cdot 52-22 \cdot 74)$ \\
\hline Western Pacific $(n=3)$ & 4810 & $4 \cdot 82 \%(4 \cdot 82-9 \cdot 84)$ & $5 \cdot 55 \%(5 \cdot 55-10 \cdot 78)$ & $5 \cdot 68 \%(5 \cdot 68-10 \cdot 78)$ \\
\hline \multicolumn{5}{|c|}{ Prevalence of intimate partner homicides among all female homicides } \\
\hline Worldwide $(n=63)$ & 133691 & $38 \cdot 55 \%(30 \cdot 84-45 \cdot 31)$ & $42 \cdot 71 \%(36 \cdot 16-58 \cdot 05)$ & $47 \cdot 36 \%(38 \cdot 55-59 \cdot 64)$ \\
\hline High-income countries $(n=36)$ & 115515 & $41 \cdot 19 \%(30 \cdot 84-44 \cdot 45)$ & $44.95 \%(42.09-58.05)$ & $48 \cdot 56 \%(42 \cdot 77-61 \cdot 31)$ \\
\hline Africa $(n=4)$ & 6219 & $40 \cdot 11 \%(38 \cdot 55-41 \cdot 67)$ & $42 \cdot 24 \%(31 \cdot 93-45 \cdot 72)$ & $44 \cdot 80 \%(42 \cdot 25-47 \cdot 36)$ \\
\hline Americas $(n=15)$ & 9658 & $40 \cdot 54 \%(7 \cdot 51-54 \cdot 84)$ & $42 \cdot 54 \%(11 \cdot 43-59 \cdot 26)$ & $42 \cdot 60 \%(11 \cdot 51-59 \cdot 64)$ \\
\hline Eastern Mediterranean $(\mathrm{n}=2)$ & 887 & $14 \cdot 41 \%(5 \cdot 26-23 \cdot 56)$ & $15 \cdot 23 \%(5 \cdot 56-24 \cdot 90)$ & $15 \cdot 28 \%(5 \cdot 58-24 \cdot 98)$ \\
\hline Low-income and middle-income Europe $(n=3)$ & 200 & $20 \cdot 00 \%(1 \cdot 82-37 \cdot 78)$ & $20 \cdot 40 \%(1.86-38 \cdot 53)$ & $20 \cdot 41 \%(1 \cdot 86-38 \cdot 55)$ \\
\hline Southeast Asia $(n=1)$ & 80 & $58 \cdot 75 \%(58 \cdot 75-58 \cdot 75)$ & $62 \cdot 10 \%(62 \cdot 10-62 \cdot 10)$ & $62 \cdot 30 \%(62 \cdot 30-62 \cdot 30)$ \\
\hline Western Pacific $(n=2)$ & 1132 & $19 \cdot 12 \%(19 \cdot 12-21 \cdot 29)$ & $20 \cdot 22 \%(20 \cdot 22-22 \cdot 51)$ & $20 \cdot 28 \%(20 \cdot 28-22 \cdot 58)$ \\
\hline \multicolumn{5}{|c|}{ Prevalence of intimate partner homicides among all male homicides } \\
\hline Worldwide $(n=28)$ & 373077 & $6 \cdot 28 \%(3 \cdot 13-6 \cdot 34)$ & $6 \cdot 47 \%(4 \cdot 42-7 \cdot 15)$ & $6 \cdot 48 \%(5 \cdot 34-7 \cdot 29)$ \\
\hline High-income countries ( $\mathrm{n}=18$ ) & 364410 & $6 \cdot 28 \%(3 \cdot 13-6 \cdot 34)$ & $6 \cdot 59 \%(4 \cdot 42,7 \cdot 15)$ & $6 \cdot 60 \%(5 \cdot 34-7 \cdot 29)$ \\
\hline Africa $(n=3)$ & 235 & $4 \cdot 12 \%(1 \cdot 55-6 \cdot 38)$ & $4 \cdot 36 \%(1 \cdot 56-6 \cdot 47)$ & $4 \cdot 41 \%(1 \cdot 80-6 \cdot 48)$ \\
\hline Americas $(n=2)$ & 4580 & $0.43(0.00-6.54)$ & $0.81 \%(0.00-11.27)$ & $4 \cdot 00(0 \cdot 00-23 \cdot 60)$ \\
\hline Eastern Mediterranean $(\mathrm{n}=0)$ & .. &.. & .. & .. \\
\hline Low-income and middle-income Europe $(n=2)$ & 226 & $3 \cdot 59 \%(3 \cdot 18-4 \cdot 00)$ & $3 \cdot 66 \%(3 \cdot 24-4 \cdot 08)$ & $3 \cdot 66 \%(3 \cdot 24-4 \cdot 08)$ \\
\hline Southeast Asia $(n=1)$ & 334 & $0.87 \%(0.87-0.87)$ & $1 \cdot 01 \%(1 \cdot 01-1 \cdot 01)$ & $1.04 \%(1.03-1.03)$ \\
\hline Western Pacific $(n=2)$ & 3292 & $1 \cdot 33 \%(1 \cdot 33-2 \cdot 78)$ & $1 \cdot 54 \%(1 \cdot 54-3 \cdot 22)$ & $1 \cdot 58 \%(1 \cdot 58-3 \cdot 30)$ \\
\hline $\begin{array}{l}\text { Data are number of homicides or median (IQR). } n=n \\
\text { Australia, Austria, Canada, Croatia, Cyprus, Czech Re } \\
\text { Lichtenstein, Luxembourg, Malta, Monaco, Netherl }\end{array}$ & $\begin{array}{l}\text { ber of countries w } \\
\text { lic, Denmark, Eng } \\
\text { s, New Zealand, N }\end{array}$ & $\begin{array}{l}\text { he existing data. *The high-inco } \\
\text { and and Wales, Estonia, Finland } \\
\text { rway, Poland, Portugal, Scotlan }\end{array}$ & $\begin{array}{l}\text { countries (classified by the World } \\
\text { nce, Germany, Hungary, Iceland, Ir } \\
\text { ovakia, Slovenia, Spain, Sweden, S }\end{array}$ & $\begin{array}{l}\text { Bank }^{20} \text { ) included Andorra, } \\
\text { reland, Israel, Italy, Japan, } \\
\text { Switzerland, and the USA. }\end{array}$ \\
\hline
\end{tabular}




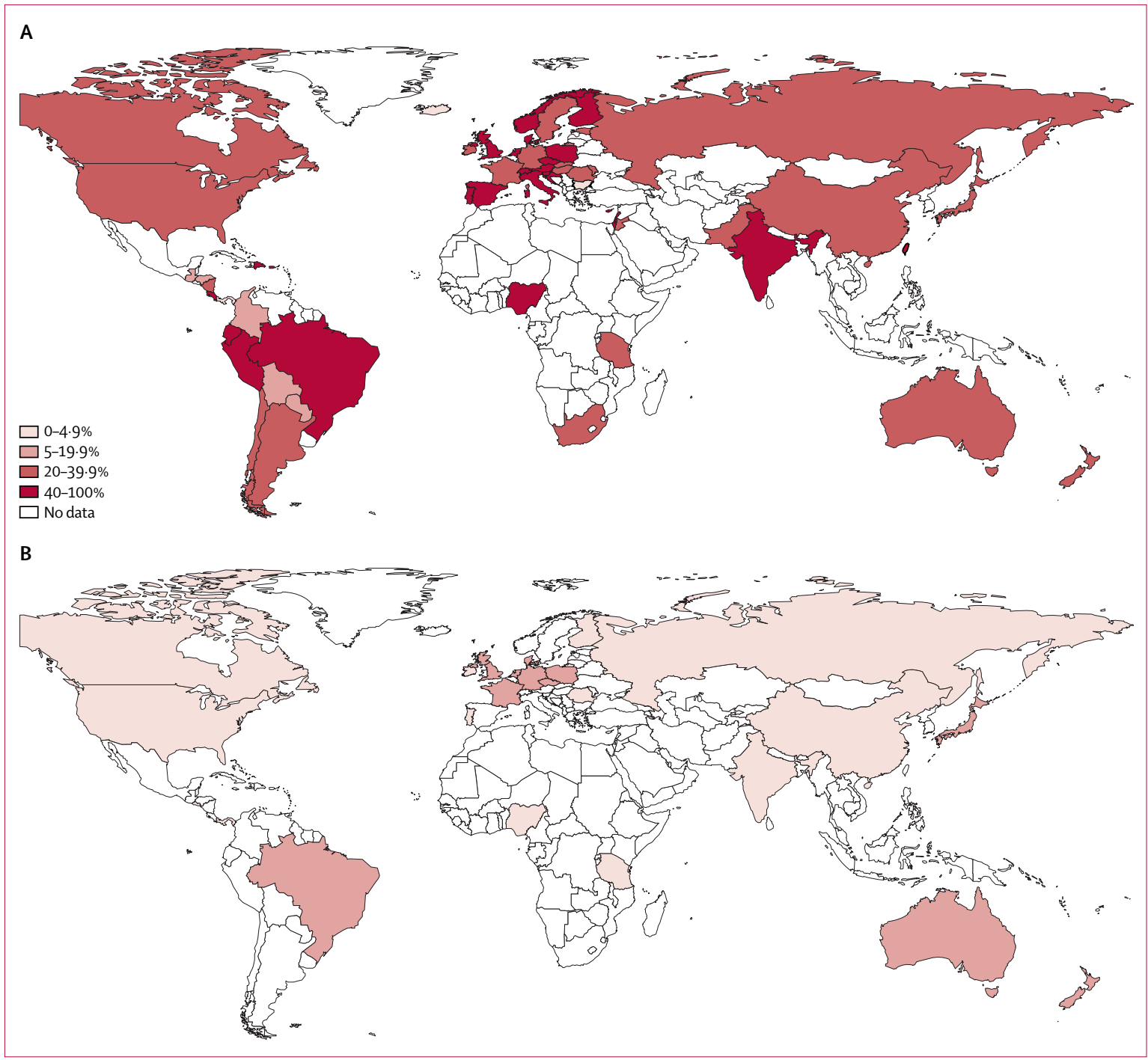

Figure 2: Prevalence of intimate partner homicide among all homicide cases, by sex

Proportion of intimate partner homicides among (A) all female and (B) all male homicides.

missing information was taken into account, and only homicides in which the victim-offender relationship was known were considered, the overall estimates for intimate partner homicides worldwide were as high as $16 \cdot 2 \%$ $(14 \cdot 1-20 \cdot 7)$, with the median percentage among female homicides increasing to $47 \cdot 4 \%(38 \cdot 5-59 \cdot 6)$ and among male homicides to $6 \cdot 5 \%(5 \cdot 3-7 \cdot 3)$. If missing cases were distributed according to the proportion of known cases, the median prevalence was $14 \cdot 1 \%(13 \cdot 0-20 \cdot 4)$ overall, $42 \cdot 7 \%(36 \cdot 2-58 \cdot 1)$ among murdered women, and $6 \cdot 5 \%$ $(5 \cdot 3-7 \cdot 3)$ among murdered men. Regional details of these estimates are reported in the table.

\section{Discussion}

Homicide is an important source of premature mortality for men and women. Overall, one in seven homicides $(13.5 \%)$ are committed by an intimate partner. The proportion of murdered women killed by a partner is six times higher than the proportion of murdered men killed by a partner $(38.6 \%$ and $6.3 \%$ of female and male homicides, respectively), reflecting both sex disparities in levels of intimate partner violence and differences in overall homicide levels between women and men.

Men are well known to be disproportionally affected by homicide, and our findings reflect established patterns of interpersonal violence, with men more likely to become victims of interpersonal violence than women, except in the domestic sphere. ${ }^{2}$ We show that consistently, across all countries where such data are collected, women's main risk of homicide is from an intimate partner. Dependent on how gaps in data are managed, the estimates range from more than a third to almost half of homicides of women being perpetrated by an intimate partner. 
The sex differences in intimate partner homicides are best shown in high-income countries such as the USA, where historical data are available. The US data show a sharp drop in intimate partner homicides among men since 1975 , and only a moderate decrease for women in the same period. ${ }^{6}$ This drop is likely to be related to increased availability and transformation in criminal justice responses ${ }^{21,22}$ to intimate partner violence and women's increased ability to leave abusive relationships, since women are more likely to murder an intimate partner while they are in the relationship, especially if the relationship is abusive. ${ }^{23,24}$

This study also draws attention to the scarcity of information about intimate partner homicide in many regions of the world, and the large amount of missing information about the victim-offender relationship, even in countries with advanced homicide monitoring data systems. This concern is important. The dynamics of intimate partner homicide are very different from the more common and more frequently studied male-male homicide. Improved information about the victim-offender relationship is crucial for devising of strategies to prevent intimate partner homicides. The gaps in information are partly due to the nature of homicide data and the poor links between the different systems-ie, police, crime, and mortuary information systems. Especially with the increasing computerisation of routine data, we hope that improved linking of such data will be feasible.

The regional differences in intimate partner homicide might represent real differences in patterns of homicide, following the argument that intimate partner homicides are more common in countries with low overall homicide rates. However, these differences might also be a product of differences in the existence, completeness, and quality of data for homicides among countries and regions, with intimate partner homicide data lacking in low-income settings, especially in Asia and Africa. As we have mentioned, data for the victimoffender relationship are most often only derived after a police investigation and these police data will only be available if the case is closed. Some murders will remain unsolved and perpetrators might never be identified, but the proportion of such unsolved murders is largely dependent on the quality of crime investigations and willingness to pursue female and intimate partner homicides. In regions such as the Americas, where male homicides are among the highest globally, the prevalence of intimate partner homicide was not among the highest reported. At the same time, this region had poor overall homicide reporting mechanisms, large amounts of missing information about the victimoffender relationship, and few studies investigating intimate partner homicides among men as compared with studies among women.

In addition to the limitations posed by the available data for intimate partner homicides, there are also some potential limitations of this study's methods. Data were restricted to one estimate per country year to avoid double-counting for countries with more than one estimate per year and to ensure that studies only providing a measure of intimate partner homicide for a specific time period would be included. However, this approach could have led to overestimation or underestimation of intimate partner homicides in countries where intimate partner homicide rates were averaged across several years if there was a notable fall or increase in intimate partner homicide rates. ${ }^{6.8}$ Favouring national representative studies over small-scale regional studies meant that we had more nationally representative data, but could have potentially led us to exclude strong regional studies (for example, where triangulation methods were used to reduce the amount of missing information ${ }^{22}$ ). Because of the restricted availability of data across settings, our review was not able to differentiate between different forms of intimate relationship, such as same-sex partnerships, or to distinguish whether the perpetrator was a current or former partner. We were not able to provide further information about the circumstances of the homicide.

An important limitation is that in a large percentage of our data we did not have information about the perpetrator-victim status. Because of this missing information, in our analysis we produced the most conservative estimate, which assumes that homicide cases with missing information are non-partner homicides ${ }^{25}$ and also explored how the estimates varied under different plausible assumptions.

Despite these limitations, and our resulting focus on conservative estimates of intimate partner homicide, our findings underscore the high prevalence of intimate partner homicides, especially among women. Any homicide is an immense tragedy. The human costs of intimate partner homicide also go far beyond the individual murder; they often involve the murder of family members or bystanders, such as the couple's children, relatives, neighbours, allies, friends, lawyers, and new partners, ${ }^{26}$ and have longstanding effects on remaining family members and friends. Surviving children not only lose the murdered parent, but also the perpetrator to prison or suicide, and face a drastic change in their social environment. ${ }^{27,28}$

The high prevalence of and the sex differences in intimate partner homicides have clear implications for efforts to prevent lethal and near-lethal intimate partner violence. Such homicides are often the ultimate outcome of a failed societal and health and criminal justice service response to intimate partner violence. The health sector needs to improve identification of and response to intimate partner violence, including assessing the severity of violence and potential homicide risk among women experiencing intimate partner violence. ${ }^{21} \mathrm{~A}$ range of safety assessment aids have been developed, and protocols for their use in different service settings need to be considered and evaluated. ${ }^{29-31}$ 
The criminal justice system cannot ignore that intimate partner homicides are an important proportion of female homicides. An improved criminal justice system response to intimate partner violence is needed both as an aim in itself, but also as part of any strategy to reduce homicide. As well as appropriate response to incidents of violence reported, policies to reduce the risk of homicide-including, for example, laws to restrict firearm access to perpetrators of intimate partner violence and other strategies targeting perpetrators ${ }^{32,33}$ - are needed. Understanding of the true magnitude of the issue is hampered by existing data systems, and workable approaches to systematically compile information about the victim-offender relationship are needed. The prevention of homicide is an important policy goal in every country and the prevention of intimate partner homicides is a crucial part of this aim, particularly for women.

\section{Contributors}

HS, KD, NA, JC, CW, and CGM participated in the study design. HS and AR did the systematic review and double-screened all abstracts and full texts. HS extracted all the data, after agreement with AR on the first ten studies. HS surveyed all statistical offices, home offices, ministries of justice, and police headquarters and searched their homepages. HS analysed the data and HS, KD, NA, JC, CW, and CGM interpreted the findings. HS wrote the first draft of the report. All authors revised and approved the final report before submission.

\section{Conflicts of interest}

We declare that we have no conflicts of interest.

\section{Acknowledgments}

The study was supported with funding provided by WHO. The Sigrid Rausing Trust and the UK Economic and Social Research Council supported the time of KD and CW.

\section{References}

1 UN Office on Drugs and Crime. Global study on homicide 2011. Vienna: UNODC, 2011.

2 Krug EG, Mercy JA, Dahlberg LL, Zwi AB. The world report on violence and health. Lancet 2002; 360: 1083-88.

3 Gartner R, Parker RN. Cross-national evidence on homicide and the age structure of the population. Soc Forces 1990; 69: 351-71.

4 Gartner R, McCarthy B. The social distribution of femicide in urban Canada, 1921-1988. Law Soc Rev 1991; 25: 287-311.

5 Wilson MI, Daly M. Who kills whom in spouse killings? On the exceptional sex ratio of spousal homicides in the United States. Criminology 1992; 30: 189-216.

6 Cooper A, Smith EL. Homicide trends in the United States, 1980-2008. Washington, DC: Bureau of Justice Statistics, 2011.

7 Smith K, Coleman K, Eder S, Hall P. Homicides, firearm offences and intimate violence 2009/10. Supplementary volume 2 to crime in England and Wales 2009/10. London: Home Office, 2011.

8 Abrahams N, Mathews S, Martin L, Lombard C, Jewkes R. Intimate partner femicide in South Africa in 1999 and 2009. PLoS Med 2013; 10: e1001412.

9 Block CR, Block R. Margo Wilson's contributions to the Chicago homicide dataset: sexual rivalry and sexual jealousy. Homicide Stud 2012; 16: 404-27.

10 Block CR, Christakos A. Intimate partner homicide in Chicago over 29 years. Crime Deling 1995; 41: 496-526.

11 Sanmartín J, Iborra I, García Y, Martínez P. III informe internacional: violencia contra la mujer en las relaciones de pareja: estadísticas y legislación (III international report: partner violence against women: statistics and legislation). Valencia: Centro Reina Sofía para el Estudio de la Violencia, 2010.
12 Geneva Declaration Secretariat. Global burden of armed violence 2011: lethal encounters. Cambridge: Cambridge University Press, 2011.

13 Sanmartín J, Iborra I, García Y, Martínez P. II informe internacional. violencia contra la mujer en las relaciones de pareja: estadísticas y legislación (II international report: partner violence against women: statistics and legislation). Valencia: Centro Reina Sofía para el Estudio de la Violencia, 2007.

14 Sanmartín J, Molina A, García Y, para el Estudio CRS. Informe internacional 2003: violencia contra la mujer en las relaciones de pareja: estadísticas y legislación (international report 2003: partner violence against women: statistics and legislation). Valencia: Centro Reina Sofía para el Estudio de la Violencia, 2003.

15 Lim SS, Vos T, Flaxman AD, et al. A comparative risk assessment of burden of disease and injury attributable to 67 risk factors and risk factor clusters in 21 regions, 1990-2010: a systematic analysis for the Global Burden of Disease Study 2010. Lancet 2013; 380: 2224-60.

16 Moher D, Liberati A, Tetzlaff J, Altman DG. Preferred reporting items for systematic reviews and meta-analyses: the PRISMA statement. PLoS Med 2009; 6: e1000097.

17 Dador J, Llaja J. Feminicidio: monitoreo sobre feminicidio/ femicidio en Bolivia, Ecuador, Paraguay, Perú y República Dominicana. Lima: CLADEM; 2008.

18 Riedel M, Best J. Patterns in intimate partner homicide California, 1987-1996. Homicide Stud 1998; 2: 305-20.

19 Paulozzi LJ, Saltzman LE, Thompson MP, Holmgreen P. Surveillance for homicide among intimate partners-United States, 1981-1998. MMWR Surveill Summ 2001; 50: 1-16.

20 World Bank. Country and lending groups. http://data.worldbank. org/about/country-classifications/country-and-lending-groups (accessed April 10, 2013).

21 Browne A, Williams KR, Dutton DG. Homicide between intimate partners: a 20 year review. In: Smith MD, Zahn MA, ed. Homicide: a sourcebook of social research. Thousand Oaks, CA: Sage, 1999: 149-64.

22 Campbell JC, Glass N, Sharps PW, Laughon K, Bloom T. Intimate partner homicide review and implications of research and policy. Trauma Violence Abuse 2007; 8: 246-69.

23 Johnson $\mathrm{H}$, Hotton T. Losing control homicide risk in estranged and intact intimate relationships. Homicide Stud 2003; 7: 58-84.

24 Wilson M, Daly M. Spousal homicide risk and estrangement. Violence Vict 1993; 8: 3-16.

25 Regoeczi WC, Riedel M. The application of missing data estimation models to the problem of unknown victim/offender relationships in homicide cases. J Quant Criminol 2003; 19: 155-83.

26 Dobash RP, Dobash RE. Who died? The murder of collaterals related to intimate partner conflict. Violence Against Women 2012; 18: 662-71.

27 Kaplan T. Marital conflict by proxy after father kills mother: the family therapist as an expert witness in court. Fam Process 1998; 37: 479-94.

28 Lewandowski LA, McFarlane J, Campbell JC, Gary F, Barenski C. "He killed my mommy!" Murder or attempted murder of a child's mother. J Fam Violence 2004; 19: 211-20.

29 Campbell J, Sharps P, Glass N. Risk assessment for intimate partner violence. In: Pinard G-F, Pagani L, eds. Clinical assessment of dangerousness: empirical contributions. New York: Cambridge University Press, 2000: 136-57.

30 Kropp PR, Hart SD, Belfrage H. Brief spousal assault form for the evaluation of risk (B-SAFER). User manual. Vancouver: ProActive ReSolutions, 2005.

31 Hilton NZ, Harris GT, Rice ME, Houghton RE, Eke AW. An indepth actuarial assessment for wife assault recidivism: the domestic violence risk appraisal guide. Law Hum Behav 2008; 32: 150-63.

32 Vigdor ER, Mercy JA. Do laws restricting access to firearms by domestic violence offenders prevent intimate partner homicide? Eval Rev 2006; 30: 313-46.

33 Murphy CM, Ting LA. Interventions for perpetrators of intimate partner violence: a review of efficacy research and recent trends. Partner Abuse 2010; 1: 26-44.

(C) 2013. World Health Organization. Published by Elsevier Ltd/Inc/BV. All rights reserved. 


\section{What is the scale of intimate partner homicide?}

Intimate partner homicides are fatal violent attacks perpetrated by intimate partners, ${ }^{1}$ and are often the extreme and unplanned consequence of abusive relationships. Although recognised as an important risk factor for death and disability among women, previous country-level assessments ${ }^{2,3}$ and the recent Global Burden of Disease Study 2010 (GBD 2010) ${ }^{4}$ have not considered the extent of intimate partner violence among male victims.

In The Lancet, Heidi Stöckl and colleagues ${ }^{5}$ present estimates of global and regional prevalence of intimate partner homicide based on a systematic review and survey of 169 national statistical offices undertaken as part of the GBD 2010 comparative risk assessment. An inclusive definition of intimate partner was used, including current, former, and same-sex partners and both male and female victims. Data were obtained for 66 countries, showing substantial information gaps. Furthermore, $20 \%$ of the homicide data had missing information about the victim-perpetrator relationship. A frequently used method to impute missing values for homicide statistics is to use contextual information, such as information about the mechanism or place of injury and characteristics of the perpetrator. However, these data were absent in most included studies.

The investigators used three different approaches to deal with missing information about the victimperpetrator relationship. For the low-level (conservative) estimates, they treated homicides with missing information as non-partner homicides. For the high-level estimates they excluded the homicide cases with missing victim-perpetrator relationship information. This approach could potentially lead to overestimation of the proportion of intimate partner homicide cases, since intimate partner homicides could arguably be solved more easily and might be more likely to be reported than are homicides perpetrated by strangers or acquaintances. For mid-level estimates, Stöckl and colleagues redistributed the cases with missing information to the known cases of intimate and non-intimate partner homicide assuming that information about the victim-perpetrator relationship was missing at random.

As expected, Stöckl and colleagues' findings reflect sex disparities in the occurrence of intimate partner homicide. On the basis of low-level estimates, they found that overall
13.5\% (IQR 9.2-18.2) of homicides were committed by an intimate partner, a proportion six times higher for female homicides $(38.6 \%, 30.8-45.3)$ than male homicides $(6.3 \%, 3 \cdot 1-6.3) .^{5}$ Although the male estimates did not vary substantially in the sensitivity analysis, the high estimate for women was almost half of all homicides and closer to the proportion of femicides perpetrated by an intimate partner reported in South Africa. ${ }^{6}$ A surprising implication of the findings is the extent of male victims of intimate partner homicide. Globally in 2010 almost half a million people are estimated to have been murdered, $^{7}$ and $80 \%$ of homicide victims were male. If $6.3 \%$ of these male homicides were perpetrated by an intimate partner this would equate to about 25000 intimate partner homicides in which the victim was male, or a ratio of 1.53 women murdered by a partner for each man that was murdered by a partner, worldwide.

The observed regional differences in intimate partner homicide need to be interpreted with caution. Although they might represent real differences in patterns of homicide, they could also be due to differences in the completeness and quality of data for homicides. The absence of data in some regions might also reflect cultural, financial, or religious factors. In certain countries, cultural killings of women, to reinstate the lost honour of a family and so-called dowry deaths, are often not treated as crimes.

Stöckl and colleagues' study draws attention to the enormous difficulties in measurement of intimate

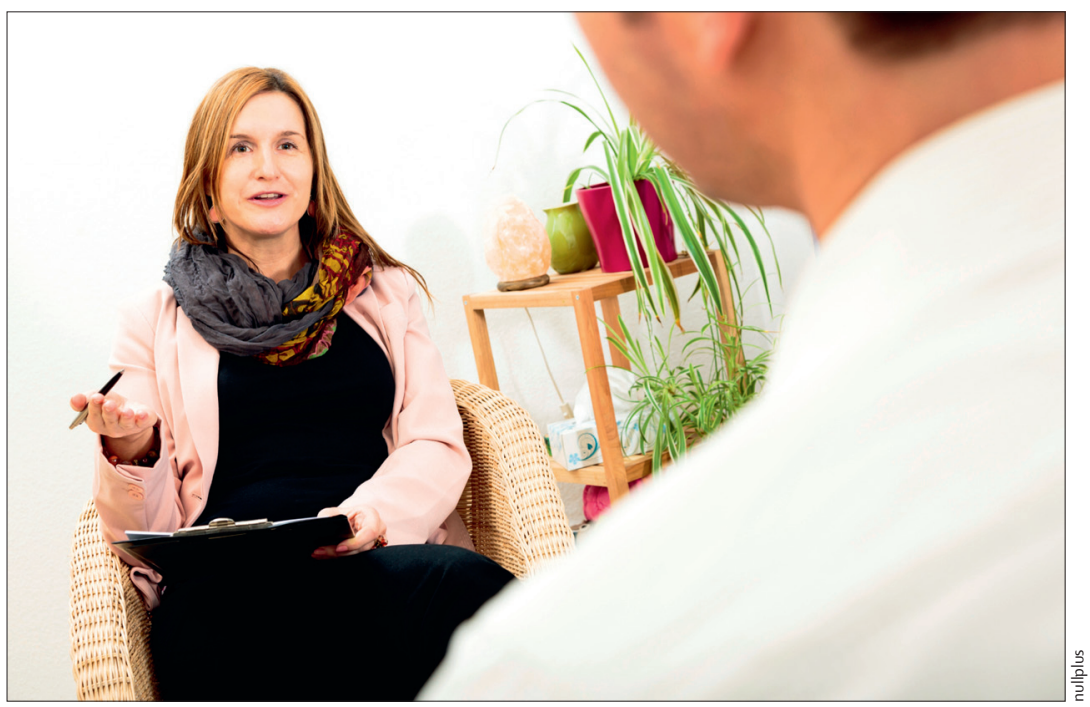

Published Online June 20, 2013 S0140-6736(13)61255-6 See Online/Articles http://dx.doi.org/10.1016/ S0140-6736(13)61030-2 http://dx.doi.org/10.1016/ 
partner homicide and the need to improve data. Improved information about victim-perpetrator relationship is crucial to inform prevention strategies. Where routine data do not provide such information reliably, good quality sample studies are needed. Ideally, such improved data could be combined with meta-analysis to explore the global variation in prevalence of intimate partner homicides.

Despite data limitations, and substantial uncertainty as to the exact prevalence of intimate partner homicide among male and female victims in different regions, these findings have important implications for efforts to prevent intimate partner homicides and the need for further research. Emphasising the importance of health services in prevention, Jewkes ${ }^{8}$ recently drew attention to a need to develop and test new directions for health professionals, because routine identification of abused women and standard interventions do not result in improved health. Future work should also consider prevention of intimate partner violence perpetration by men with interventions designed to support men in building non-violent identities. ${ }^{8,9}$ There is also a need for other sectors to respond, and an improved criminal justice system response to intimate partner violence is required as well as laws to restrict firearm access to perpetrators of intimate partner violence..$^{5,10}$

Intimate partner homicides result mainly from conflicts associated with abusive relationships, jealousy, revenge, or the termination of a relationship, but the motive can also be financial gain, emphasising the complexity of homicides involving intimate partners and the need for improved understanding of the determinants and situation in which such acts occur. Stöckl and colleagues' findings raise important questions about the scale and dynamics of intimate partner homicide: are the countries with available data representative of all countries? Were the perpetrators current or former partners? What is the proportion of heterosexual versus homosexua partnerships? Has there been a falling or increasing trend in intimate partner homicides over time?

Prevention of homicide of women and men by intimate partners is important. Research into the complex issues related to intimate relationships can only be undertaken if improved data are collected in a systematic fashion.

\section{*Rosana E Norman, Debbie Bradshaw}

Queensland Children's Medical Research Institute, University of Queensland, Herston, QLD 4029, Australia (REN); School of Population Health, University of Queensland, Herston, QLD, Australia (REN); and Burden of Disease Research Unit, South African Medical Research Council, Tygerberg, Cape Town, South Africa (DB)

r.norman@sph.uq.edu.au

We declare that we have no conflicts of interest.

1 Abrahams N, Mathews S, Martin LJ, Lombard C, Jewkes R. Intimate partne femicide in South Africa in 1999 and 2009. PLoS Med 2013; 10: e1001412.

2 Begg S, Vos T, Barker B, Stevenson C, Stanley L, Lopez A. Burden of disease and injury in Australia in the new millennium: measuring health loss from diseases, injuries and risk factors. Med J Aust 2008; 188: 36-40.

3 Norman $\mathrm{R}$, Schneider M, Bradshaw D, et al. Interpersonal violence: an important risk factor for disease and injury in South Africa. Popul Health Metr 2010; 8: 32

4 Lim SS, VosT, Flaxman AD, et al. A comparative risk assessment of burden of disease and injury attributable to 67 risk factors and risk factor clusters in 21 regions, 1990-2010: a systematic analysis for the Global Burden of Disease Study 2010. Lancet 2012; 380: 2224-60.

5 Stöckl H, Devries K, Rotstein A, et al. The global prevalence of intimate partner homicide: a systematic review. Lancet 2013; published online June 20. http://dx.doi.org/10.1016/S0140-6736(13)61030-2.

6 Abrahams N, Jewkes R, Martin LJ, Mathews S, Vetten L, Lombard C. Mortality of women from intimate partner violence in South Africa: a national epidemiological study. Violence Vict 2009; 24: 546-56.

7 Lozano R, Naghavi M, Foreman K, et al. Global and regional mortality from 235 causes of death for 20 age groups in 1990 and 2010: a systematic analysis for the Global Burden of Disease Study 2010. Lancet 2012; 380: 2095-128

8 Jewkes R. Intimate partner violence: the end of routine screening Lancet 2013; published online April 16. http://dx.doi.org/10.1016/ S0140-6736(13)60584-X.

9 Jewkes R, Nduna M, Levin J, et al. Impact of Stepping Stones on incidence of HIV and HSV-2 and sexual behaviour in rural South Africa: cluste randomised controlled trial. BMJ 2008; 337: a506.

10 Vigdor ER, Mercy JA. Do laws restricting access to firearms by domestic violence offenders prevent intimate partner homicide? Eval Rev 2006; 30: 313-46. 